03,04,09,12,13

\title{
ЭПР и люминесценция пористого кремния
}

\author{
(C) Н.Е. Демидова ${ }^{1,2}$, E.C. Демидов ${ }^{1, \uparrow, ~ В . В . ~ К а р з а н о в ~}{ }^{1}$ \\ ${ }^{1}$ Нижегородский государственный университет им. Н.И. Лобачевского, \\ Нижний Новгород, Россия \\ ${ }^{2}$ Нижегородский государственный архитектурно-строительный университет, \\ Нижний Новгород, Россия \\ ฯ E-mail:demidov@phys.unn.ru
}

Поступила в Редакцию 22 октября 2020 г.

В окончательной редакции 22 октября 2020 г.

Принята к публикации 18 ноября 2020 г.

\begin{abstract}
Представлены данные исследования ЭПР, фотолюминесценции (ФЛ) и токопереноса в пористом кремнии (ПК) на $\mathrm{Si}$ КДБ-0.3 и КЭС-0.01, окисленного термическим изохронным $10 \mathrm{~min}$ отжигом на воздухе при температурах Tann от 20 до $900^{\circ} \mathrm{C}$, а также в $\mathrm{HNO}_{3}$ с целью дальнейшего прояснения природы $P_{b}$-центров безызлучательной рекомбинации. Максимальный квантовый выход ФЛ наблюдался при химическом окислении ПК на кремнии марки КДБ-0.3. Имеет место антикорреляция интенсивности ФЛ и ЭПР $P_{b}$-центров в интервале $T_{\text {ann }}=(20-300)^{\circ} \mathrm{C}$. Обнаружена немонотонная зависимость интенсивности ЭПР $P_{b}$-центров от $T_{\text {ann }}$ с минимумом около $700^{\circ} \mathrm{C}$. Слабая ФЛ ПК с Tann около $700^{\circ} \mathrm{C}$ при минимуме ЭПР $P_{b}$-центров означает возникновение с отжигом других центров безызлучательной рекомбинации. Падение проводимости ПК с ростом Tann связано с распадом волокон $\mathrm{Si}$ в ПК на мелкие гранулы, сквозь которые происходит дискретное туннелирование носителей тока.
\end{abstract}

Ключевые слова: полупроводники, пористый кремний, гетеронаноструктура, фотолюминесценция, электронный парамагнитный резонанс, перенос тока.

DOI: 10.21883/FTT.2021.03.50588.228

\section{1. Введение}

Объектом многочисленных исследований, отображенных в обзорах $[1,2]$, является наноразмерная гетероструктура - пористый кремний (ПК), который согласно [3] представляет собой трехфазную систему из волокон или гранул кремния, окруженных слоем оксида кремния и воздухом между ними. Особенно большой интерес к ПК возник в связи с обнаружением в нем видимой люминесценцией и возможным проявлением квантово-размерных эффектов. Пористый кремний обладает уникальными оптическими, люминесцентными, и электрофизическими свойствами $[1,2]$. Фотолюминесценция (ФЛ) ПК наблюдалась в широком диапазоне от ближнего ИК-излучения до голубого свечения [2]. Методом электронного парамагнитного резонанса (ЭПР) в этом материале обнаружены так называемые $P_{b}$-центры безызлучательной рекомбинации, с которыми связывают подавление красной ФЛ [2]. В настоящей работе представлены данные исследования ЭПР, ФЛ и токопереноса в ПК, окисленного термическим отжигом на воздухе при температурах до $900^{\circ} \mathrm{C}$ и также в водном раствоpe $\mathrm{HNO}_{3}$ с целью дальнейшего прояснения природы $P_{b}$-центров.

\section{2. Эксперимент}

ПК формировался анодным травлением кристаллов $\mathrm{Si}$ $n$ - и $p$-типа (КЭС 0.01 и КДБ 0.3) в смеси $\mathrm{HF}, \mathrm{C}_{2} \mathrm{H}_{5} \mathrm{OH}$ и $\mathrm{H}_{2} \mathrm{O}$. Для усиления люминесцентных свойств слои ПК окислялись в 10\% водном растворе азотной кислоты и затем травились в плавиковой кислоте с последующей промывкой в деионизованной воде. Высокий уровень легирования подложек выбирался для минимизации вклада области пространственного заряда в поперечный транспорт тока. Проводился изохронный окислительный $10 \mathrm{~min}$ отжиг образцов до $900^{\circ} \mathrm{C}$. Поперечный электротранспорт определялся по виду ВАХ диодных структур In/ПК/Si c прослойкой ПК. ФЛ измерялась при комнатной температуре в диапазоне длин волн 500-900 nm при возбуждении импульсным азотным лазером ИЛГИ-503 на длине волны $\lambda_{\text {exc }}=337 \mathrm{~nm}$, ЭПР на спектрометре фирмы Брукер при $293 \mathrm{~K}$.

\section{3. Результаты и обсуждение}

Анализ данных для плоской границы $\mathrm{Si}-\mathrm{SiO}_{2}$ и в различных нанокристаллах кремния в обзорах $[4,5]$ показал несоответствия известной молекулярной модели $P_{b}$-центров. В связи с естественной поверхностной плотностью атомов кремния, по молекулярной модели, поверхностная плотность $P_{b}$-центров на границе кремнийоксид кремния должна быть $\sim 10^{15} \mathrm{~cm}^{2}$. Но на практике эта величина на 3-4 порядка меньше [6]. С точки зрения молекулярной модели, не понятно, почему $P_{b}$-центры чувствительны к изменению толщины $\mathrm{SiO}_{2}$ и, по данным [6], пропадают при его толщине меньше $5 \mathrm{~nm}$. Кроме того, при таком богатом разнообразии, ожидаемых 


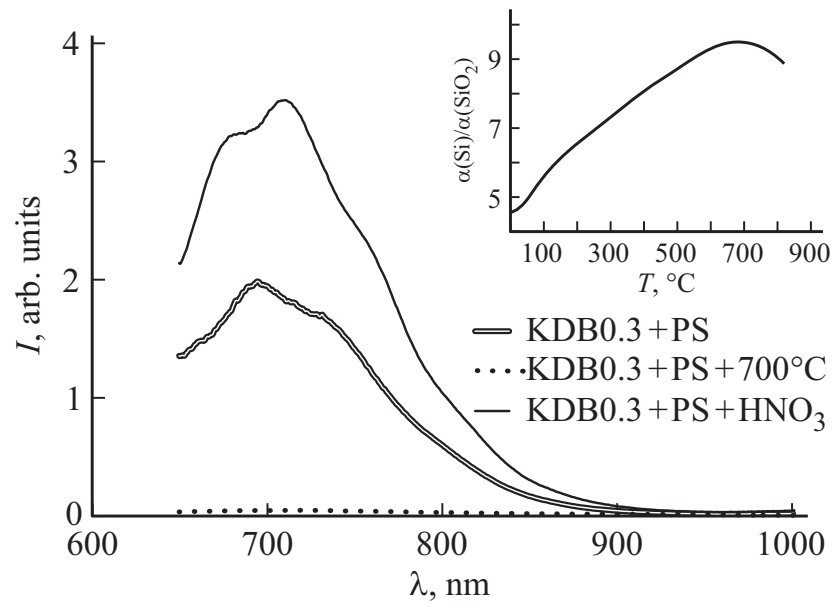

Рис. 1. Спектры ФЛ ПК на КДБ 0.3 исходного образца $\mathrm{KDB} 0.3+\mathrm{PS}$, отожженного $10 \mathrm{~min}$ при $700^{\circ} \mathrm{C}$ на воздухе KDB0.3 + PS + 700C, выдержанного в $10 \%$ водном растворе $\mathrm{HNO}_{3}-\mathrm{KDB} 0.3+\mathrm{PS}+\mathrm{HNO}_{3}$. На вставке температурная зависимость отношения коэффициентов термического расширения $\alpha$ кремния и оксида кремния.

по молекулярной модели, вариантов связей, на гетерогранице $\mathrm{Si}-\mathrm{SiO}_{2}$ наблюдались всего один или два вида парамагнитных центров [7,8]. Поверхность кремния на гетерогранице не является атомарно гладкой. Поэтому, по молекулярной модели, не должно быть существенной разницы в ЭПР на границах с ориентацией поверхности $\mathrm{Si}$ (111) и (100), что противоречит эксперименту.

В $[4,5]$ приводятся доводы, что $P_{b}$-центрами являются более делокализованные электронные состояния как в ориентированных в ПК или не ориентированных в других гетероструктурах $\mathrm{Si}-\mathrm{SiO}_{2}$ нанокристаллах $\mathrm{Si}$, так и вблизи плоской границы окисленного кремния. Было высказано предположение, что эти $P_{b}$-центры являются результатом сильных напряжений в кремнии и возникновением дислокаций вблизи границы с оксидом кремния при его образовании. При высокотемпературном окислительном отжиге такие напряжения должно быть особенно велики из-за окисления и увеличения напряжений при охлаждении из-за более, чем девятикратной разницы в коэффициентах термического расширения $\mathrm{Si}$ и $\mathrm{SiO}_{2}$ (см. вставку на рис. 1). Согласно данным [5], оказалось, что окисление при $700^{\circ} \mathrm{C}$ ПК на КДБ 0.3 почти полностью подавляет в нем ФЛ, вероятно, вследствие ухудшения квантового выхода люминесценции мелких наночастиц кремния в ПК из-за наведения в них дислокаций сильными механическими напряжениями, а холодное окисление в азотной кислоте с малыми механическими напряжениями увеличивает интенсивность ФЛ (рис. 1).

Более детальное, чем на рис. 1 измерение изменения спектров ФЛ ПК на КЭС-0.01 и на КДБ-0.3 от температуры окислительного отжига $T_{\text {ann }}$ показано на рис. 2. ФЛ ПК на КЭС 0.01 до $800 \mathrm{~nm}$ является слабой и сложно зависит от $T_{\text {ann. }}$. Начиная с $T_{\text {ann }}=200^{\circ} \mathrm{C}$ появляется широкая полоса ФЛ с максимумом около $570 \mathrm{~nm}$, которая ослабляется начиная с $500^{\circ} \mathrm{C}$. Также при $T_{\text {ann }}=200^{\circ} \mathrm{C}$ появляется длинноволновая сравнительно интенсивная широкая полоса ФЛ с максимумом около $850 \mathrm{~nm}$, которая немонотонно зависит от температуры отжига, и природа которой не известна. При $T_{\text {ann }}=700$ и $800^{\circ} \mathrm{C}$ длинноволновая ФЛ усиливается и расширяется в коротковолновую область до $650 \mathrm{~nm}$. В случае ПК на КДБ-0.3 имеется известная интенсивная красно-оранже-
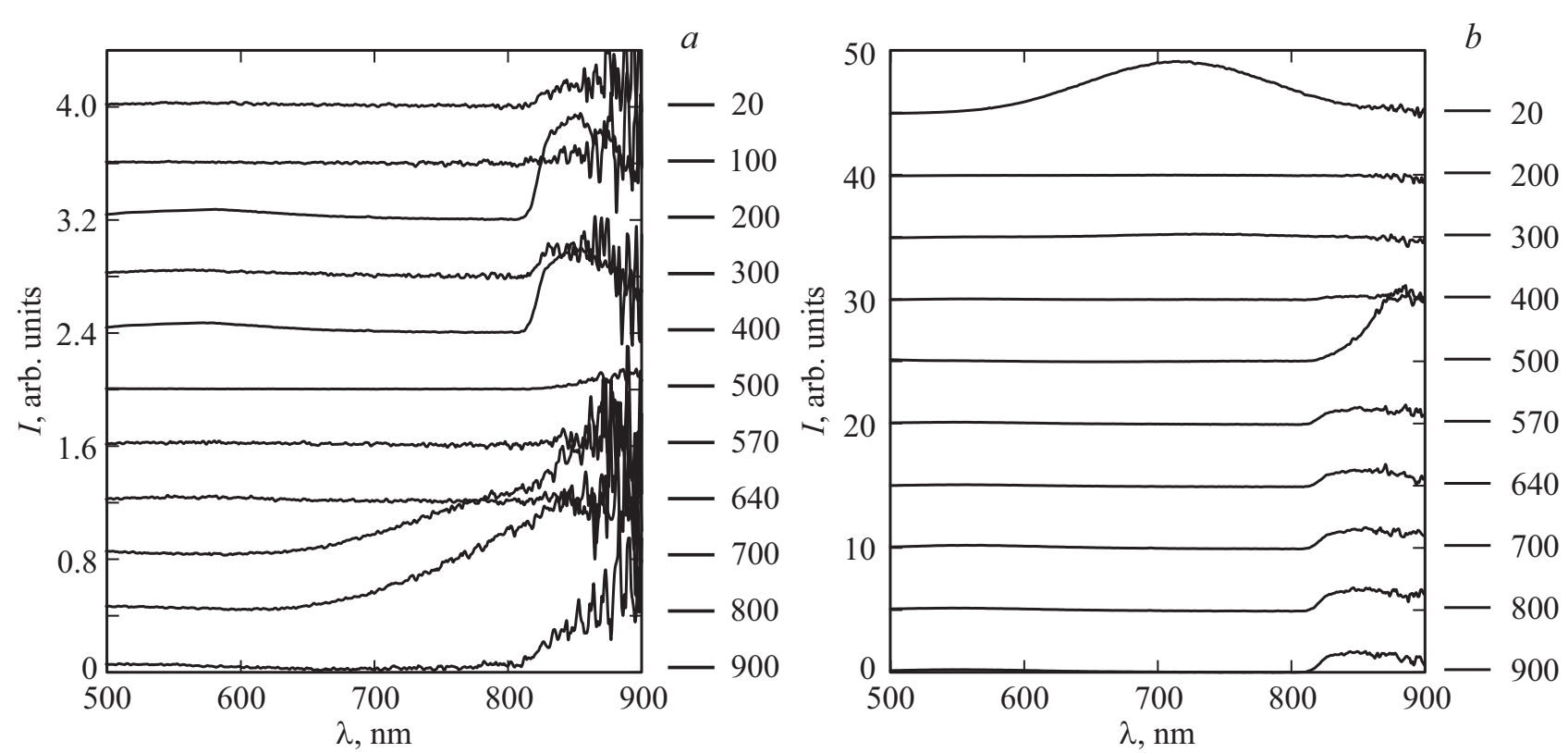

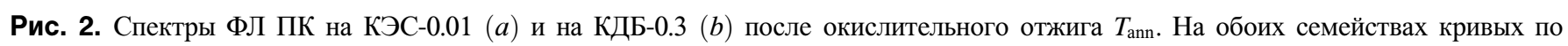
вертикали справа $T_{\mathrm{ann}}$ в градусах Цельсия. 


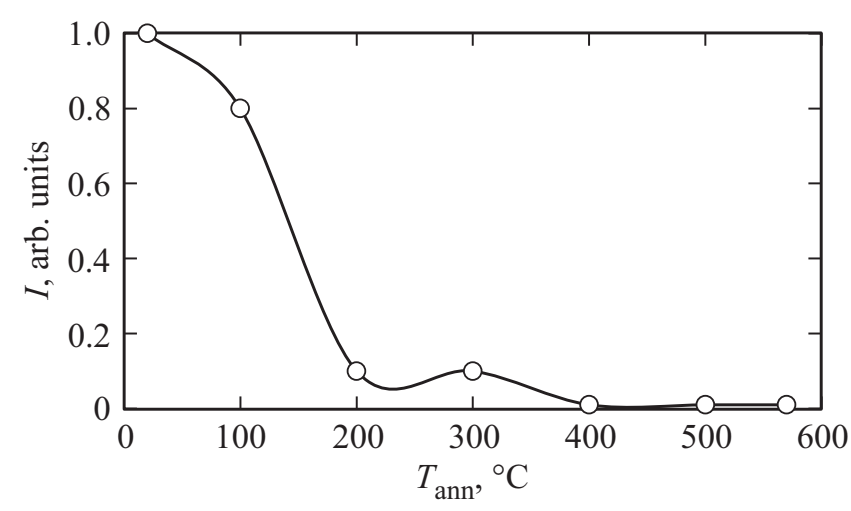

Рис. 3. Зависимость от температуры окислительного отжига $T_{\text {ann }}$ интенсивности $I$ ФЛ ПК на КДБ-0.3 на длине волны света $650 \mathrm{~nm}$.

вая ФЛ с максимумом около $720 \mathrm{~nm}$. С отжигом она неожиданно быстро спадает начиная с $T_{\text {ann }}=200^{\circ} \mathrm{C}$. При $T_{\text {ann }}=570^{\circ} \mathrm{C}$ появляется, как и в случае ПК на КЭС-0.01, длинноволновая на порядок более интенсивная чем у ПК на КЭС-0.01 широкая полоса ФЛ с максимумом около $850 \mathrm{~nm}$. Вероятно, что эта полоса связана с ФЛ неких центров в оксиде кремния, доля которого растет с увеличением $T_{\text {ann }}$.

Зависимость интенсивности $650 \mathrm{~nm}$ ФЛ ПК на

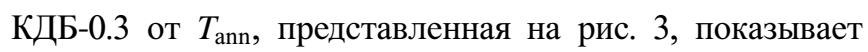
ее почти монотонный спад до $400^{\circ} \mathrm{C}$. Вместе с тем, как видно на рис. 4, для ПК на КЭС-0.01, наблюдается сложная немонотонная зависимость интенсивности ЭПР $P_{b}$-центров от $T_{\text {ann. }}$ В интервале от 20 до $300^{\circ} \mathrm{C}$ происходит рост числа парамагнитных $P_{b}$-центров, имеет место известная антикорреляция в изменении интенсивности
ФЛ на рис. 3 и ЭПР $P_{b}$-центров на рис. 4. Однако выше $400^{\circ} \mathrm{C}$ происходит спад амплитуды спектра ЭПР до минимума около $700^{\circ} \mathrm{C}$, затем ее рост до $900^{\circ} \mathrm{C}$, что означает сохранение наночастиц $\mathrm{Si}$ в ПК до $900^{\circ} \mathrm{C}$. Отметим, что рост числа $P_{b}$-центров происходит на склонах колоколообразной температурной зависимости отношения коэффициентов термического расширения кремния и оксида кремния на вставке на рис. 1. Вероятно, около $T_{\text {ann }}=700^{\circ} \mathrm{C}$ происходит максимальное измельчение термическими напряжениями образовавшихся при формировании при комнатной температуре пористого слоя волокон $\mathrm{Si}$ в ПК на мелкие гранулы [9], в результате которого уменьшается средняя по объему плотность дислокаций в наночастицах кремния.

Сигнал ЭПР $P_{b}$-центров в ПК на КДБ-0.3 много слабее, чем в случае КЭС-0.01, вероятно из-за менее благоприятного для этих центров положения уровня Ферми. Тем не менее, до $700^{\circ} \mathrm{C}$ тенденция та же, что и у ПК на $n$-Si, что делает правомерными вышеприведенные выводы об антикорреляции ФЛ и ЭПР. Слабая ФЛ ПК с $T_{\text {ann }}$ около $700^{\circ} \mathrm{C}$ при минимуме амплитуды спектра ЭПР $P_{b}$-центров означает возникновение с отжигом других центров безызлучательной рекомбинации.

В поперечном транспорте тока наблюдалось падение проводимости ПК на КДБ-0.3 и КЭС-0.01 с ростом $T_{\text {ann }}$, связанное с распадом волокон $\mathrm{Si}$ в ПК на мелкие гранулы, сквозь которые происходит дискретное туннелирование носителей тока $[5,6]$. Нелинейные вольтамперные характеристики подобны приведенным в статье [10].

\section{Благодарности}

Авторы благодарны А.С. Абросимову за помощь в измерении спектров люминесценции.
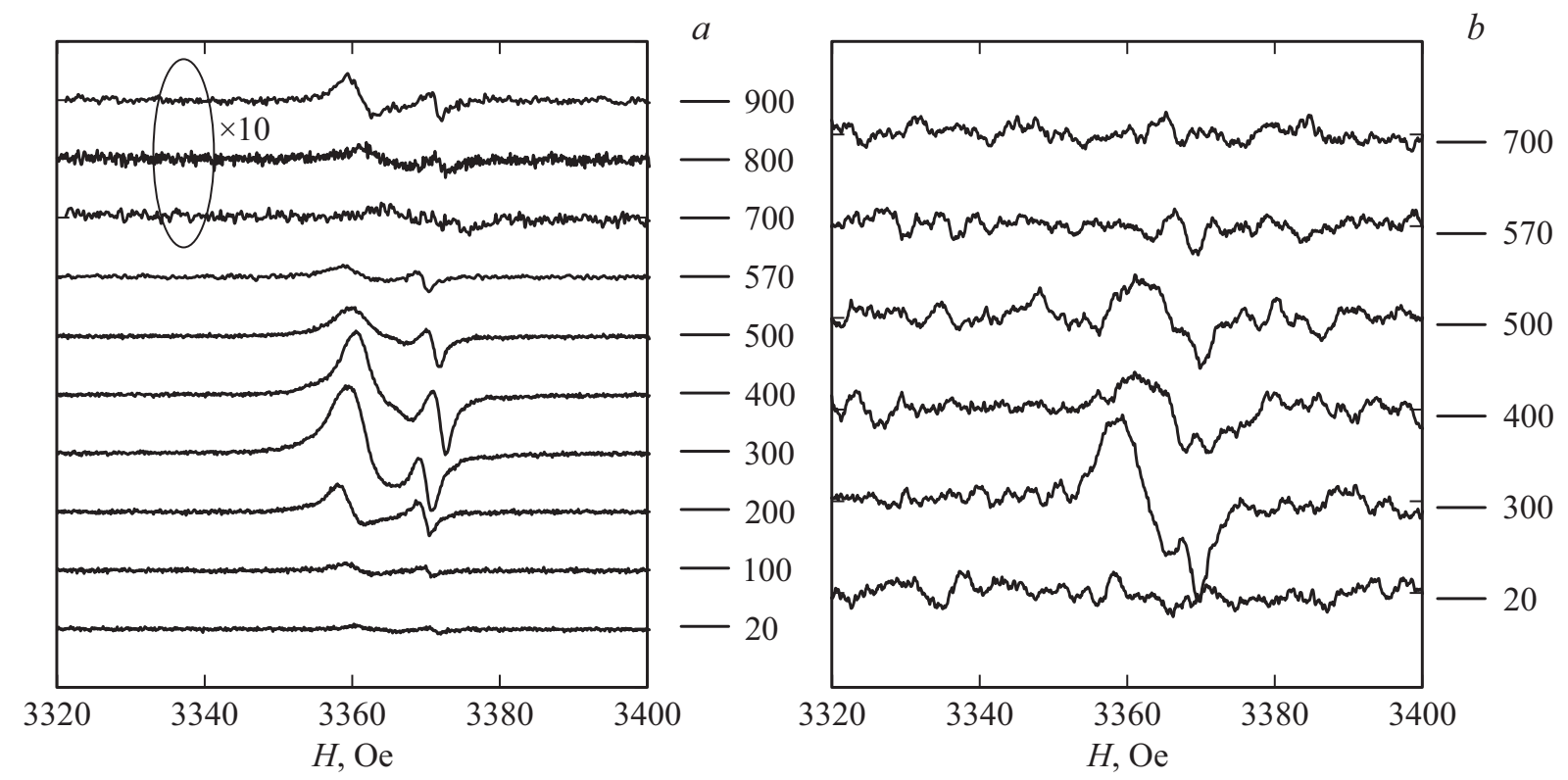

Рис. 4. Спектры ЭПР ПК на и КЭС-0.01 (a) КДБ-0.3 (b). Справа приведена температура изохронного 10 min окислительного отжига на воздухе в градусах Цельсия. 


\section{Финансирование работы}

Исследование выполнено по теме инициативных НИР Нижегородского государственного университета им. Н.И. Лобачевского 2019 г. „Исследование возможностей синтеза новых полупроводниковых и магнитных наноразмерных структур“.

\section{Конфликт интересов}

Авторы заявляют, что у них отсутствует конфликт интересов.

\section{Список литературы}

[1] Handbook of Porous Silicon / Ed. Leigh Canham. Springer International Publishing, Switzerland (2014).

[2] O. Bisi, S. Ossicini, L. Pavesi. Surf. Sci. Rep., 38, 1 (2000).

[3] E.S. Demidov, V.V. Karzanov, V.G. Shengurov. JETPL 67, 839 (1998).

[4] Е.С. Демидов, Н.Е. Демидова. Вестн. ННГУ. Сер. В 1, 8 , 22 (2005).

[5] Н.Е. Демидова. Автореф. канд. дис. ННГУ. Нижний Новгород ( 2010).

[6] W.E. Carlos, S.M. Prokes, J. Appl. Phys. 78, 2129 (1995).

[7] P.J. Caplan, E.H. Poindexter, B.E. Deal, R.R. Razouk. J. Appl. Phys. 50, 5847 (1979).

[8] E.H. Poindexter, G.J. Gerardi, M.-E. Rueckel, P.J. Caplan, N.M. Johnson, D.K. Biegelsen. J. Appl. Phys., 56, 2844 (1984).

[9] Е.С. Демидов, Н.Е. Демидова, В.В. Карзанов, К.А. Марков, В.В. Сдобняков. ФТТ 51, 1894 (2009).

[10] Е.С. Демидов, А.С. Абросимов, Н.Е. Демидова, В.В. Карзанов. ФТТ 59, 245 (2017).

Редактор Д.В. Жуманов 